\title{
Ensino a distância: conhecimentos, habilidades e competências necessárias para o professor do ensino superior
}

\author{
Distance learning: knowledge, skills and competences necessary for the higher education teacher \\ Educación a distancia: conocimientos, habilidades y competencias necesarias para el docente de \\ educación superior
}

Recebido: 14/01/2022 | Revisado: 22/01/2022 | Aceito: 22/01/2022 | Publicado: 24/01/2022

Samuel Dos Santos Junio

ORCID: https://orcid.org/0000-0003-1500-4939 Universidade de Trás-os-Montes e Alto Douro, Portugal E-mail: samuel.santos@ifro.edu.br

Alecsandro Marian da Silva

ORCID: https://orcid.org/0000-0001-7925-8810 Instituto Federal de Educação, Ciência e Tecnologia de Rondônia, Brasil E-mail: alecsandroadm@gmail.com

Guilherme Tadaki Tazo Gaspar

ORCID: https://orcid.org/0000-0002-8664-0871 Instituto Federal de Educação, Ciência e Tecnologia de Rondônia, Brasil E-mail: guilherme.gaspar@ifro.edu.br Caren Stela Máximo Batista

ORCID: https://orcid.org/0000-0001-6220-041X Instituto Federal de Educação, Ciência e Tecnologia de Rondônia, Brasil E-mail: caren.batista@ifro.edu.br

Cássia Luciana de Melo Lima

ORCID: https://orcid.org/0000-0002-7263-2010 Instituto Federal de Educação, Ciência e Tecnologia de Rondônia, Brasil E-mail: cassia.lima@ifro.edu.br

\begin{abstract}
Resumo
O presente estudo trata do tema do conhecimentos, habilidades e competências necessárias para a docencia no ensino superior na modalidade a distância e seu objetivo é analisar as características necessárias à prática docente para a qualificação do processo ensino-aprendizagem na educação a distância. Para alcançar este objetivo contextualiza o ensino a distância, determina os conhecimentos, habilidades e competências pertinentes à docência a distância no ensino superior onde destaca-se a importância destes parâmetros para o exito na formação do aluno. Por meio de pesquisa bibliográfica qualitativa, conclui que uma formação de qualidade deve adequar-se a uma sociedade plural, heterogênea, dialética e controversa na qual o conhecimento, as habilidades e as competências se encontram também em constante evolução e transformação.
\end{abstract}

Palavras-chave: Ensino a distância; Docência; Qualificação; Formação.

\begin{abstract}
This study deals with the theme of knowledge, skills and competences necessary for teaching in higher education in distance education and its objective is to analyze the characteristics necessary for teaching practice for the qualification of the teaching-learning process in distance education. To achieve this objective, it contextualizes distance education, determines the knowledge, skills and competences relevant to distance teaching in higher education, where the importance of these parameters for success in the student's education is highlighted. Through qualitative bibliographic research, it concludes that quality training must be adapted to a plural, heterogeneous, dialectical and controversial society in which knowledge, skills and competences are also in constant evolution and transformation.
\end{abstract}

Keywords: Distance learning; Teaching; Qualification; Formation.

\section{Resumen}

Este estudio aborda la temática de los conocimientos, habilidades y competencias necesarias para la docencia en la educación superior en la educación a distancia y su objetivo es analizar las características necesarias para la práctica docente para la calificación del proceso de enseñanza-aprendizaje en la educación a distancia. Para lograr este objetivo, contextualiza la educación a distancia, determina los conocimientos, habilidades y competencias relevantes para la enseñanza a distancia en la educación superior, donde se destaca la importancia de estos parámetros para el éxito en la educación del estudiante. A través de la investigación bibliográfica cualitativa, concluye que la formación 
de calidad debe adaptarse a una sociedad plural, heterogénea, dialéctica y controvertida en la que los conocimientos, habilidades y competencias también están en constante evolución y transformación.

Palabras clave: Educación a distancia; Enseñando; Calificación; Formación.

\section{Introdução}

A tecnologia possui um campo de abrangência cada vez maior sobre toda a sociedade, influindo em fatores como alterações na configuração dos símbolos e dos interesses.

A tecnológica influi também na modificação da estrutura psicológica dos processos que envolvem a memória estendendo-a para além das dimensões biológicas humanas, na incorporação de novos estímulos e ampliação do repertório de informações, conhecimentos e formas de aprendizagem.

Nesse sentido, especialmente difunde na modificação da natureza das comunidades de aprendizagem conhecidas, instaurando a ideia de um mundo no qual a distância física inexiste.

No que se refere à educação, a tecnologia, embora não seja algo novo, promove o ensino atemporal e assincronico marca o sentido da união entre educação e tecnologia e, no caso das universidades, sendo a produção e a transmissão do conhecimento campos mais próximos, a tecnologia rompe com uma estrutura burocrática, pedagógica e simbólica de conhecimentos fracionados, criando entornos de ensino mais abertos.

Ainda, a tecnologia requer dos docentes o desenvolvimento de conhecimentos, habilidades e competências que lhes permitam aproveitar as ferramentas e recursos tecnológicos otimizando-os para melhorar a efetividade da aprendizagem e da formação. Os meios tecnológicos, ao mesmo tempo em que ampliaram as ofertas educativas e flexibilizaram a dinâmica do ensino e da aprendizagem, lançam constantes desafios para o aperfeiçoamento da prática docente.

Diante dessa realidade, no âmbito da educação o perfil do docente do ensino a distância se modifica, exigindo-se que sua prática didático-pedagógica envolva aspectos que se estendem para além da simples capacidade para transmitir conteúdos e promover atividades de diálogo e de orientações para a compreensão de temas discutidos em uma sala presencial.

Nesse sentido, o problema de pesquisa considerado na realização deste estudo é: Em que sentido o conhecimento, as habilidades e as competências do professor do ensino superior no ensino a distância devem ser orientadas para qualificar o processo de formação dos alunos?

A abordagem do tema do conhecimento, habilidade e competências necessárias para o professor do ensino superior na modalidade a distância é justificada relevância e atualidade dessa questão.

Justifica-se também pela importância cada vez maior que as ferramentas tecnológicas adquirem para a educação e, no ensino a distância, trazem questões prementes que desafiam a refletir sobre a formação de professores, o acesso à informação e ao conhecimento por parte dos alunos e seus novos contornos, que se refletem, principalmente, em uma nova forma de conceber a formação universitária.

O objetivo geral do estudo é analisar as características necessárias à prática docente para a qualificação do processo ensino-aprendizagem na educação a distância.

Os objetivos específicos são: contextualizar o ensino a distância; determinar os conhecimentos, habilidades e competências pertinentes à docência a distância no ensino superior e destacar a importância destes parâmetros para o resultado final da formação do aluno.

\section{Metodologia}

A metodologia do estudo é a pesquisa bibliográfica, qualitativa e exploratória, possibilitando a maior abrangência possível das diversas dimensões da questão investigada através das informações obtidas, catalogadas e comentadas sob uma perspectiva qualitativa para orientar a conclusão geral sobre o tema e resposta ao problema de pesquisa. 
A metodologia é constituída pela estratégia de análise bibliográfica e documental, que implica em um conjunto ordenado de procedimentos de busca por soluções, atento ao objeto de estudo (Severino, 2007). Configura-se a partir de uma abordagem qualitativa, pois, de acordo com Lüdke e André (1986), apresenta algumas características, entre as quais podem ser salientadas: o ambiente natural (o mundo real) como fonte para a coleta de dados e a interação entre sujeito, pesquisador e objeto. Para esta pesquisa, foram utilizados acervo digital, com auxílio de internet para realizações revisões bibliográficas, artigos, monografias e dissertações, Trata-se de uma revisão narrativa, que não pega todas informações da literatura sobre o assunto mas somente parte, visando atingir os objetivos da pesquisa.

\section{Resultados e Discussão}

\section{1 Contextualizando a educação a distância}

A educação a distância, de acordo com a consideração de Kenski (2012) pode ser definida como "um conjunto de experiências educativas no qual a díade educador-educando se encontra separada por coordenadas espaço-temporais nas quais o controle volitivo do processo é assumido pelo aluno".

O elemento central nesse processo é a distância, o qual distingue qualitativamente essa modalidade de ensino do ensino presencial, fazendo referência à separação do docente e do educando, mas, ao mesmo tempo, preconizando um aluno isolado dos companheiros de estudo e dos recursos de aprendizagem. Nessa perspectiva, compreende Kenski (2012) que a distância representaria um elemento negativo, um "espaço vazio" que é preenchido pela tecnologia para adquirir um significado formativo.

Complementarmente, Tori (2017) assinala que a educação a distância proporciona a utilização de recursos e ferramentas tecnológicas para gerar condições que emulam o ensino presencial, mas são diferentes deste. Esses recursos e ferramentas têm o poder de permitir contatos mais estreitos entre os agentes do processo (professor e alunos).

No mesmo sentido, observa Kenski (2012) que uma de suas principais características é a interação, sendo que a principal ação do aluno é exercida individualmente sobre objetos de aprendizagem, constantemente em diálogo com professores e, ocasionalmente, em alguns modelos, em interação e diálogo com os colegas.

Considera Behar (2014) que na educação a distância os objetos de aprendizagem devem ser "autoconteúdos" capazes de permitir a aprendizagem do aluno, facilitando a compreensão, graduando o avanço, regulando o esforço e a motivação. Disso sugiram propostas teóricas interessantes, como a do Diálogo Didático Simulado, contexto no qual a qualidade de uma proposta de educação a distância pode ser avaliada, em grande medida, pela qualidade dos materiais que são oferecidos aos alunos.

Acrescenta Behar (2014) que o conceito de educação virtual se baseia nessa ideia de qualidade, utilizando serviços disponíveis na web para oferecer uma forma de aprendizagem que se adequa ao tempo e necessidade do aluno, facilita o manejo das informaçães e o acesso aos conteúdos por intermediação das tecnologias da informação e comunicação, que proporcionam ferramentas que promovem o processo formativo.

O ensino superior à distância, conforme Behar (2014), geralmente se apresenta como uma alternativa ou complemento da formação presencial e permite responder às necessidades de formação e capacitação dos alunos. Esta modalidade traz uma nova cultura de aprendizagem que promove um conhecimento intuitivo, construtivo, criativo e crítico, possibilitando assim o acesso à formação, capacitação, aprimoramento daqueles que não podem formar-se através de outras modalidades de aprendizagem.

Freitas (2013) observa que seu conceito faz referência à aprendizagem a distância facilitada pela tecnologia, representando uma forma avançada da metodologia de formação, já que incorpora ao processo ensino-aprendizagem as TICs permitindo reunir professores, alunos e conteúdos em torno de uma aula virtual. Para isso, utiliza ferramentas ou aplicações de 
hipertexto como suportes do processo ensino-aprendizagem.

Um aspecto altamente relevante da educação a distância, para Freitas (2013), se refere ao software e à sua compatibilidade para desenvolver cursos e materiais didáticos virtuais. A plataforma em que se desenvolvem os cursos é uma arquitetura hardware ou uma estrutura de suporte (framework) de software que permite alojar diferentes aulas virtuais. O processo formativo ocorre em um entorno virtual, ou seja, em um espaço criado virtualmente com a intenção de que um aluno obtenha experiências de aprendizagem através de recursos/materiais formativos, sob a supervisão e interação com um professor.

Neste tipo de aula virtual, para Freitas (2013), é possível identificar três grandes dimensões pedagógicas: dimensão informativa (recursos, materiais, etc.); dimensão prática (ações e tarefas) e dimensão tutorial e avaliativa (funções docentes). Assim, o aluno tem acesso e desenvolve uma série de ações similares às que acontecem no âmbito presencial, como conversar, ler documentos, realizar exercícios, formular perguntas ao professor, trabalhar em equipe, etc. Tudo isso ocorre de forma simulada sem que ocorra uma interação física entre os participantes.

Conforme Valente (2012), nesse novo espaço são geradas novas regras interativas e de intervenção pedagógica, bem como se desenvolve e se aprimora um sentido de comunidade que permite processos de negociação e construção coletiva de significados. O ensino, nessa modalidade, supõe uma diminuição da hierarquia, uma modificação dos papéis tradicionais e um estímulo para o trabalho autônomo do aluno.

Nesse contexto, os participantes se encontram em diálogo constante e de criação conjunta, os conteúdos deixam de ser o centro e ocupam um lugar preponderante as atividades que os atores realizam.

\section{2 Conhecimentos, habilidades e competências do docente do ensino superior}

De um modo geral, o aprendizado se refere à aquisição de conhecimentos construídos através dos tempos e aprimorados constantemente. Schon (2013) pondera que considerando a evolução das ciências cognitivas nos últimos anos é possível perceber que há certo consenso sobre outras formas de enfrentar os processos de aprendizagem.

Isso implica, como analisa Schon (2013), alterar os processos de ensino, já que a partir dessa perspectiva já não é suficiente aprofundar o conhecimento de áreas especificas, sendo necessário incorporar à aprendizagem a reflexão quanto à estrutura do conhecimento e o seu papel na sociedade.

Schon (2013) afirma que a formação de professores deve contemplar conhecimentos e competências cuja referência curricular siga um modelo que supere as concepções e as opções reducionistas e dogmáticas da aprendizagem. Para promover a formação de competências e de habilidades cognitivas e linguísticas é imprescindível a promoção, desenvolvimento e avaliação de competências de pensamento científico.

Contudo, Schon (2013) adverte que desenvolver uma definição operativa de competência científica é algo complexo, pois este é um conceito polissêmico e ambíguo. De qualquer modo, pode ser resumido em saber, saber fazer, ser, viver juntamente com as outras pessoas, em situações nas quais se deve decidir como agir, problematizar e aplicar o conhecimento.

Da mesma forma, a competência científica é um tipo de conhecimento complexo que sempre se exerce em um contexto de forma eficiente em três dimensões: saber, saber fazer e ser.

Seguindo a mesma análise, Martins (2015) comenta que uma competência científica seria argumentar (capacidade de aspecto cognitivo linguístico) e desde essa perspectiva um sujeito competente seria capaz de usar o conhecimento para identificar problemas e gerar explicações e argumentações com fundamento baseado no conhecimento teórico-científico.

Nesse sentido, é a formação deve desenvolver e implementar atividades que permitam desenvolver competências de pensamento científico que permitam ao aluno reconstruir seus conhecimentos e favoreçam uma forma de conceber o conhecimento, bem como de olhar e de interpretar o mundo e a realidade. 
Quando se trata da formação de professores, considera Martins (2015) essencial integrar o aluno de forma oportuna em âmbitos muito menos restritos que os atuais, isto é, mais amplos e mais profundos sobre a ciência, a sociedade, a educação e o processo de ensino e aprendizagem.

Da mesma forma, para Nóvoa (2015) não basta desenvolver, na formação de professores, habilidades que ensinem a resolver problemas, mas sim habilidades e competências para que sejam eles mesmos quem empreguem problemas com finalidades mais extensas e profundas.

O desafio dessa formação é educar e habilitar, formando professores para promoverem e avaliarem nos alunos competências de pensamento, de análise, de crítica e de proposições, assumindo que o contexto da aula, presencial ou não, é um laboratório em que tudo deve ser investigado para produzir conhecimento. (Nóvoa, 2015).

Quanto às competências do professor Freire (2011) afirma que a contribuição do educador à sociedade, junto aos economistas, aos sociólogos e a todos os especialistas que buscam melhorar esta sociedade é a de promover uma educação crítica, uma educação que busque superar a transitividade ingênua e chegar à transitividade crítica, ampliando e aprofundando a habilidade para captar os desafios do tempo. Essa educação coloca o homem em condições de resistir aos poderes da emocionalidade da própria transição, estando armado contra a força dos irracionalismos, dos quais era presa fácil na posição de transitividade ingênua na qual se encontrava.

À pergunta sobre como realizar uma educação capaz de proporcionar os meios para superar atitudes mágicas ou ingênuas diante da própria realidade, ajudando o homem a criar o mundo de signos gráficos Freire propõe um método ativo, dialogal e participante:

E que é o diálogo? É uma relação horizontal de A com B. Nasce de uma matriz crítica e gera criticidade (Jaspers). Nutre-se do amor, da humildade, da esperança, da fé, da confiança. Por isso, só o diálogo comunica. E quando os dois polos do diálogo se ligam assim, com amor, com esperança, com fé um no outro, se fazem críticos na busca de algo. Instala-se, então, uma relação de simpatia entre ambos. Só aí há comunicação. "O diálogo é, portanto, o indispensável caminho", diz Jaspers, "não somente nas questões vitais para nossa ordenação política, mas todos os sentidos do nosso ser. Somente pela virtude da crença, contudo, tem o diálogo estímulo e significação: pela crença no homem e nas suas possibilidades, pela crença de que somente chego a ser eu mesmo quando os demais também cheguem a ser eles mesmos". Era o diálogo que opúnhamos ao antidiálogo, tão entranhado em nossa formação histórico-cultural, tão presente e ao mesmo tempo tão antagônico ao clima de transição. (Freire, 2011).

No que se refere à formação de professores para o ensino superior Morin (2007) defende a construção de uma autêntica pertinência social, que não é sinônimo de adequação às exigências do desenvolvimento do mercado e da indústria, mas uma obrigação da universidade de prestar contas à sociedade já que, definitivamente, ambas não são elementos antagônicos, mas complementares.

Dessa forma, o objetivo vital é a realização de uma "reforma do pensamento que viabilize e permita o emprego total da inteligência, [uma] reforma não pragmática, mas paradigmática, concernente a nossa aptidão para organizar o conhecimento". (Morin, 2007).

Ainda, considera:

Uma reforma da Universidade suscita um paradoxo: não se pode reformar a instituição (as estruturas universitárias), se anteriormente as mentes não forem reformadas; mas só se pode reformar as mentes se a instituição for previamente reformada. (Morin, 2007).

É necessário, pois, reformar o pensamento, que responde a uma necessidade social-chave: “formar cidadãos capazes de enfrentar os problemas de seu tempo". Esta seria a conformação de uma educação de reforço da democracia, de ampliação da competência dos cidadãos para compreender contextual e globalmente os problemas. (Morin, 2007). 
É também a conformação de uma educação a qual considera que "é primordial aprender a contextualizar e melhor que isso, a globalizar, isto é, a saber situar um conhecimento num conjunto organizado". (Morin, 2007).

Dessa premissa deriva, conforme Morin (2007), a ideia de reaprender a pensar, religar a cultura da ciência e a cultura das humanidades, compreender a diversidade, problematizar questões e disciplinas, "mantendo nelas a relação humana e, assim, atingir a unidade complexa do homem".

Em oposição à massificação, assim como Freire, Morin alude à democratização do saber:

Torna-se efetivamente impossível democratizar um saber fechado e esoterizado por sua própria natureza. É cada vez mais possível admitir uma reforma de pensamento que permita enfrentar o imenso desafio que nos encurrala com a seguinte alternativa: ou continuamos a sofrer o bombardeio de inumeráveis informações que nos chegam em avalanche cotidianamente pelos jornais, rádios, TV, ou então passamos a confiar nos sistemas de pensamento que retêm apenas as informações daquilo que os confirma ou lhes é inteligível, rejeitando como erro ou ilusão tudo o que lhes desmente ou lhes é incompreensível. (Morin, 2007)

Este problema se coloca para o conhecimento cotidiano e de tudo o que conforma a complexidade social e científica: “o desafio da complexidade no mundo contemporâneo constitui um problema-chave do pensamento e da ação política" e, por extensão inegável, da educação. (Morin, 2007).

Finalmente, Morin (2007) alude a sete buracos negros na educação: conhecimento, conhecimento pertinente, condição humana, compreensão humana, incerteza, era planetária, antropoética (ética em escala humana). Esses núcleos são o desafio para pensar o ensino superior. Repetindo a grande pergunta de Marx sobre quem educará os educadores, afirma a necessidade de que eduquem a si próprios, identificando as necessidades éticas e sociais.

Considerando esses desafios é possível citar a proposição de Bates (2016), que sugere uma série de passos e recomendações que considera úteis como habilidades e competências do professor e que, por sua generalidade e flexibilidade, facilitam a ele promover um ensino a distância de qualidade no ensino superior:

a) Habilidade para a delimitação do problema: definir claramente o problema a ser abordado no material a ser trabalhado, o que implica uma visão global da situação, tanto do ponto de vista das necessidades institucionais como da informação a ser desenvolvida, bem como as características dos destinatários e seu contexto;

b) Habilidade para a elaboração de objetivos: em função do problema definido, o professor procede ao estabelecimento daquilo que propõe que seja alcançado através dos materiais a serem produzidos, o que deve observar o vínculo existente entre os objetivos e a solução do problema;

c) Competência de avaliação e seleção de meios: intimamente ligado ao processo de fixação de objetivos, é a opção pelos meios mais adequados dentre os selecionados. Os critérios que devem prevalecer nessa seleção devem estar relacionados, basicamente, com a natureza dos objetivos e dos conteúdos;

d) Competência para o planejamento da produção: após selecionar os meios, o professor planifica a sua produção, levando em conta os requerimentos de custos temporais e materiais relativos a cada meio, as etapas do modelo, os tempos e os responsáveis;

e) Habilidade para a elaboração de conteúdo: em função do que foi planejado, seguindo as orientações gerais do processo e as pautas específicas elaboradas, observa o objetivo perseguido pelo conteúdo; proporcionando a informação clara, exemplos e explicações extras; sugestões de bibliografia para ampliar as informações;

f) Habilidade para fazer a adaptação mútua entre os conteúdos, os objetivos e os meios: essa adaptação é feita à forma própria de linguagem do meio ou dos meios selecionados, levando em conta a função que cumprirá dentro do programa;

g) Competência para a produção de material: produção técnica do material, conformado às características específicas e próprias do meio; 
h) Competência de controle de qualidade: revisão crítica do material, levando em consideração os parâmetros de qualidade já definidos, os estilos, as linguagens, os desenhos, etc., julgando tanto a qualidade acadêmica como técnica do material. Os meios didáticos utilizados devem ser analisados a partir de suas condições concretas de função e, principalmente, por suas funções pedagógicas, as quais possam ser cumpridas em relação às necessidades educativas dos alunos.

\subsection{A importância das características do professor para o resultado final da formação do aluno no ensino superior à distância}

Os meios, recursos e ferramentas tecnológicos aplicados à prática educativa representam uma chave para desenvolver métodos e técnicas de ação docente efetivas para a promoção da formação integral dos alunos.

A sua implementação, paralelamente à reconfiguração das práticas habituais e da visão comum a respeito do ensino e sobre a aprendizagem necessita que os professores estabeleçam uma concepção desse processo, tendo o aluno como ator principal de sua aprendizagem.

Ainda, é necessário ao professor desenvolver uma postura que seja capaz de coordenar a utilização das ferramentas tecnológicas pelos alunos, adaptando-se às necessidades do ensino a distância, articulando essas ferramentas da forma apropriada para promover a formação desses alunos. (Freitas, 2013).

Freitas (2013) também adverte que unicamente a ideia de que possa ser possível desenvolver um ensino a distância inserindo ferramentas tecnológicas e o em rede nos processos de ensino e aprendizagem tecnologias da informação e comunicação e redes que eliminem a distância física não é suficiente: é preciso que, concomitantemente ao momento em que a universidade se sirva dessas ferramentas, os professores saibam como proporcionar aos alunos instruções e possibilidades para o uso da em sua autoformação.

Como observam, complementarmente, Valentini e Soares (2014), "não basta incorporar recursos tecnológicos e esperar que a mediação através deles ocorra naturalmente, pois esse não é um processo mecânico”. Freitas (2013) também adverte que a mera incorporação de recursos das TICS aos processos de ensino, assim como a oferta de cursos à distância não permite experiências válidas, pois as TICS não se definem apenas pelo apoio que fornecem ao professor em sua tarefa. É necessário que o professor saiba como trabalhar a aprendizagem dos alunos, torná-los protagonistas da produção dos próprios conhecimentos, desenvolver competências dialógicas e de interação para auxiliá-los nesse protagonismo.

A tecnologia educativa deve ser crítica, de abordagem holística, "compreendendo a multifatorialidade de que resultam os processos interativos". (Valentini; Soares, 2014).

Indo além, enfatizam Valentini e Soares (2014) que a educação a distância não se define senão como processo e, nesse processo, a interatividade é meio e não um fim. Portanto, nada ocorre sem a mediação do professor no que se refere à questão da aprendizagem e ao conhecimento. A qualidade da educação encontra-se diretamente relacionada com sua capacidade em mobilizar recursos para efetivamente educar.

Não basta ao professor, portanto, que se mantenha restrito à utilização de materiais prontos e predefinidos. Essa atitude, além de improdutiva, caracteriza um ensino fragmentado, descomprometido para com a formação integral, reduzindose a mera "maquiagem" de um currículo cuja dinâmica é pensada para o formato online, através de ferramentas tecnológicas, mas que, na prática, é didaticamente manejado por professores que não compreendem as tecnologias como sendo poderosos instrumentos educacionais. (Valentini; Soares, 2014).

Nesse sentido, o aperfeiçoamento da prática docente é uma urgência, porque, como adverte Tori (2017), diante das TICs a experiência possui um peso maior do que a informação por si mesma e a eficiência com que o conhecimento é disponibilizado através delas é muito maior do que ocorre nas formas tradicionais de transmissão de conhecimentos.

Quanto à experiência, essa é compreendida como motor da necessidade de desenvolver positiva e construtivamente 
métodos e matérias com base em uma filosofia da experiência. De acordo com Dewey (2010), "a ideia fundamental da filosofia de educação mais nova e que lhe dá unidade é a de haver relação íntima e necessária entre os processos de nossa experiência real e a educação", ressaltando a importância de uma ideia correta da experiência.

Nesse sentido, Dewey (2010) destaca que o que permite diferenciar as experiências que podem ser consideradas como educativamente valiosas das que não o são é o princípio da continuidade experiencial, baseado no hábito, cuja característica básica é que toda experiência que é vivida modifica experiências anteriores (hábitos), afetando-os.

Esse princípio, de aplicação universal, considera as experiências como forças em movimento e impõe a quem educa a missão de ver a direção em que a experiência se move, sem impor um controle exterior, mas verificando quais atitudes conduzem a um desenvolvimento contínuo, compreendendo individualmente os alunos. (Dewey, 2010).

Por outro lado, toda experiência "modifica quem a realiza e por ela passa e a modificação afeta, quer o queiramos ou não, a qualidade das experiências subsequentes", ou seja, todas as experiências pelas quais o sujeito passa durante a vida são importantes porque formam e transformam a experiência presente. (Dewey, 2010).

$\mathrm{Na}$ atualidade, o suporte tecnológico como meio e como ferramenta cria ambientes diferenciados de aprendizagem, nos quais são construídos, como observam Straubhaar e Larose (2008, p, 61), não somente sistemas de conhecimentos, mas metassaberes, definidos como "habilidades que tornam as pessoas capazes de avaliar a pertinência dos conhecimentos processos seguidos, desenhar estratégias satisfatórias em função de suas próprias aspirações”.

Conforme Carvalho (2012), no que se refere ao professor do ensino a distância, o domínio das TICs e de suas possibilidades proporciona mais tempo, melhor embasamento e maiores possibilidades de trabalhar conteúdos, habilidades, competências e valores que promovam uma formação de efetiva qualidade que rompa não apenas a distância física, mas que elimine a distância que existe entre o aluno, o conhecimento, a formação humana e profissional.

Dessa forma, compreende-se que um processo de formação continuada é essencial para desenvolver habilidades e competências e integrar conhecimentos que, por sua vez, se integram ao ensino como possibilidades de proporcionar uma formação satisfatória e qualitativa. Se é tarefa do professor configurar esse espaço virtual, é essencial que domine as formas pelas quais possa controlar esse processo.

Observa Castells:

Os avanços da tecnologia impactaram a tal ponto os processos de ensino e de aprendizagem que uma cultura nova surgiu em relação a estratégias e ferramentas a serem empregadas. A internet, por exemplo, a realidade virtual, espaços sincrônicos e assincrônicos de comunicação, softwares projetados especificamente para a educação, são mudanças importantes em termos tecnológicos, configurando ambientes de aprendizagem virtual que vêm em resposta à aspiração de estarem todas as instituições à mesma altura, torna-se imperioso que alunos e professores se capacitem para a geração de conhecimentos adequados à sua utilização no espaço educacional, desenvolvendo cada um suas próprias capacidades. (Castells, 2009).

Como TICs comportam ferramentas, produtos, técnicas ou processos, equipamentos ou métodos, essas aproximações entre os termos geram campos complementares: tecnologia educativa e tecnologias aplicadas ao ensino e educação. Se torna essencial a formação continuada de professores no trabalho com as TICs no âmbito da educação a distância para identificar a tecnologia educativa com a didática, envolvendo processos os quais permitem que se produza a aprendizagem e suas ferramentas. (Carvalho, 2012).

Deste modo, é essencial ao professor que este se mantenha atualizado quanto à evolução cultural, social e tecnológica, porque está se insere definitiva e decisivamente no âmbito da educação e influencia a sua prática pedagógica. Da mesma forma, é essencial ao professor a habilidade para reconhecer a forma pela qual essa evolução modifica o perfil dos alunos, aprofundando seus conhecimentos para ser capaz de enfrentar os desafios dessa "nova educação", tornando os alunos capazes 
de participar dos processos permanentes de democratização do acesso à educação. (Kerckhove, 2013).

A importância maior da formação de professores do ensino superior para utilizar ferramentas tecnológicas e meios digitais de forma satisfatória no ensino a distância reside, portanto, na ideia de que sua aplicação ao processo ensinoaprendizagem e sua mediação deve ser apropriada a esse ambiente e ao seu público-alvo, ou seja, deve ser adequada aos contextos, às situações e aos usuários concretos. Da mesma forma, deve também ser pertinente do ponto de vista sociocultural.

Assim, Kerckhove (2013) ressalta que a formação contínua de professores representa uma capacitação para trabalhar com tecnologias em constante evolução e aprimoramento, demandando uma formação permanente e autônoma e a disponibilidade para aprender juntamente com os alunos as infinitas possibilidades oferecidas por esse meio.

Precisamente por essas razões, se torna claro que o professor atualmente necessita contar com formação contínua, capaz de capacitá-lo a criar as condições que favoreçam aos alunos exercer a sua ação de aprender participando de situações que favoreçam essa aprendizagem, a partir da realidade contida nos meios tecnológicos. As ações, nesse caso, não implicam necessariamente em uma atividade física aparente, mas se consolidam como atividade mental e exercício intelectual. Kerckhove, 2013).

A formação contínua do professor, considerando as demandas do ensino superior a distância, oferece a possibilidade de que este transforme sua formação inicial, seu aprendizado e sua experiência, tornando-se também sujeito da própria aprendizagem. Para que esse entendimento seja renovado, observa Freitas (2013) que os docentes precisam procurar formação que permita desenvolver soluções novas, baseadas em novas visões de mundo, em novos modelos teóricos, em novas práticas e em novos modos de proporcionar o acesso a conhecimentos.

Valentini e Soares (2014), refletindo sobre a importância de uma escolha correta dos meios e das estratégias pelas quais se desenvolva o ensino mediado pela tecnologia, observam que sua eficácia se relaciona com a consideração dos seguintes critérios: a) objetivos pretendidos; b) conteúdo a transmitir; c) características dos destinatários; d) recursos disponíveis (técnicos e econômicos).

Analisando esses aspectos, pode-se determinar se o objetivo perseguido, associado ao correspondente conteúdo, requerer explicações, demonstrações, variedade e abundância, interações, análise de dados, apresentação e produção de síntese, etc. Alguns meios são mais convenientes que outros, conforme a função a que se destinam.

Para Valentini e Soares (2014), os diversos meios utilizados devem ser analisados a partir das possibilidades concretas que ofereçam como contribuição e, principalmente pelas funções pedagógicas que possam cumprir em relação às necessidades de educação específicas. Assim, sua função corresponde a:

a) favorecer a autonomia, que é requisito indispensável em um sistema de educação mediada pela tecnologia;

b) despertar a curiosidade científica no destinatário, motivando-o para que continue buscando e mantendo a atenção e o interesse;

c) relacionar os conhecimentos prévios, com os novos que são propostos;

d) facilitar o alcance dos objetivos determinados;

e) apresentar a informação adequada, esclarecendo conceitos que possam ser complexos e ajudar a esclarecer os pontos mais controvertidos;

f) dar impulso para desencadear processos de pensamento no destinatário, propondo atividades inteligentes e evitando, tanto quanto possível aquelas que estimulem somente a retenção e a repetição;

g) proporcionar a criatividade.

Silva (2010) ainda considera que os meios visuais, auditivos, audiovisuais e informáticos, impõem certas características às mensagens, havendo diferença entre transmitir uma informação em material impresso e através da internet, por exemplo. Em cada caso, “a relação dos destinatários com os meios tem características distintas, o que condiciona a própria 
estrutura das mensagens".

De qualquer modo, as decisões tomadas em relação ao conteúdo e ao caráter da educação mediada pela tecnologia têm consequências muito importantes, tanto para o aluno como para a sociedade. Estas decisões deveriam ser baseadas em uma sólida direção, no sentido de contemplar princípios e padrões necessários à educação. Os princípios descrevem características particulares e uma educação qualificada e os padrões descrevem conteúdos e processos a serem aprendidos pelos alunos. Seu conjunto é um guia para melhorar continuamente o ensino.

Ponte (2014) determina que, de um modo geral, os princípios da educação envolvem temas como equidade (expectativas altas e apoio a todos os alunos); currículo coerente, centrado em temas importantes e articulados); ensino (entender o que o aluno sabe e o que precisa aprender para orientá-lo); aprendizagem (aprender compreendendo, construir conhecimento ativamente a partir de experiências e conhecimentos anteriores); avaliação (apoiar a aprendizagem e administrar informações úteis); tecnologia (essencial ao ensino e à aprendizagem, porque influi no que se ensina e melhora a aprendizagem).

Estes seis princípios não se referem a conteúdos ou a processos específicos e, portanto, são bastante diversos dos padrões. Descrevem alguns temas cruciais, estreitamente entrelaçados com todos os programas de educação. Observa Ponte (2014) que podem influenciar o desenvolvimento das estruturas curriculares, a escolha de materiais curriculares, o planejamento dos módulos de ensino ou das lições, a formatação de avaliações, as decisões de ensino nas aulas e o estabelecimento de programas de apoio para o desenvolvimento dos professores.

Para Valente (2012) a tecnologia no ensino a distância promove a aprendizagem online que, por sua vez, pode ser considerada como uma mudança cultural: se modifica o conceito e o que significa a experiência de ensinar e de aprender.

Esta modalidade gera a possibilidade de que os alunos vivam processos interativos e comunicacionais reais, através de espaços de trabalho e atividades inovadoras.

Desta forma, para Valente (2012) os processos educativos gerados a partir das interações em espaços mediados por ferramentas tecnológicas, bem como a aplicação de propostas e marcos pedagógicos novos são espaços alternativos para a construção do conhecimento. Esses espaços são essenciais para a concepção de novos processos educativos, rompendo com a dicotomia entre educação presencial e a educação a distância.

\section{Considerações Finais}

Abordando o tema do conhecimento, habilidade e competências necessárias para o professor do ensino superior na modalidade a distância, este estudo teve como problema de pesquisa o questionamento sobre em que sentido o conhecimento, as habilidades e as competências do professor do ensino superior devem ser orientadas para qualificar o processo de formação dos alunos.

Com base nessa problemática cumpriu com o objetivo de analisar as características necessárias à prática docente para a qualificação do processo ensino-aprendizagem na educação a distância.

Inicialmente, contextualizou a educação a distância, concluindo que coloca importantes desafios aos agentes envolvidos, dentre os quais a relevância da consideração de questões adicionais como a superação da distância entre o aluno, o professor e os colegas, bem como a criação de condições para que dialogue com o professor, tutor, colegas e material, fazendo descobertas e autoconstruindo sua aprendizagem.

Como pressupostos de qualidade desse processo, tais requisitos levam à ponderação de que a qualidade não é um conceito estático, mas uma característica dos processos de ensino que indica aperfeiçoamento, melhoria, alcance de metas e, no ensino a distância, representa uma evolução que incorpora uma cultura de pensamento de autoaprendizagem, ações que consideram que a capacidade, a qualidade e o favorecimento do autoconhecimento são fundamentais à qualificação do 
processo de aprendizagem.

A segunda abordagem considerou o conhecimento, habilidades e competências do docente do ensino superior, concluindo que na docência do ensino superior à distância é necessário ao professor compreender as mudanças didáticas experimentadas no trabalho em ambiente virtual de aprendizagem.

Essa compreensão comporta a realização de um processo reflexivo sobre sua própria prática docente-científica e as diferentes ações de gestão, planejamento e avaliação de atividades, bem como sobre os conteúdos ensinados.

Isso se associa à necessidade de promoção de diversas competências de pensamento teórico-científico, associadas a habilidades e competências dialógicas, sociais e comunicacionais construídas a partir dos novos parâmetros didáticopedagógicos trazidos pelas ferramentas tecnológicas.

Por fim, abordou a importância das características do professor para o resultado final da formação do aluno no ensino superior à distância. Conclui que as habilidades e competências que se somam ao conhecimento docente permitirão estabelecer relações entre as análises teóricas e a intervenção prática em ambientes virtuais, a seleção de conteúdos, a elaboração de materiais, o desenvolvimento de novas formas e parâmetros avaliativos.

Quanto mais essas habilidades e competências se aproximem da compreensão do protagonismo do aluno em sua própria formação e da necessidade de desenvolver o pensamento científico aliado ao pensamento crítico, melhor os professores desenvolverão também nos alunos as competências para saber, saber fazer, ser, viver em comunidade, decidir como agir e problematizar o conhecimento.

Como conclusão geral, o estudo indica a possibilidade e a relevância da realização de um aprofundamento dessa temática em estudos futuros, voltados para a questão da formação dos professores para a maximização dos recursos tecnológicos como ferramentas efetivas de formação no âmbito do ensino superior à distância.

Sugere, também, a possibilidade de estudos que considerem que o avanço das tecnologias educacionais depende da apropriação e da adequação de processos e recursos tecnológicos às necessidades educativas dos alunos, pois uma formação de qualidade deve adequar-se a uma sociedade plural, heterogênea, dialética e controversa na qual o conhecimento, as habilidades e as competências se encontram também em constante evolução e transformação.

Finalmente, a partir dos pressupostos evocados, afirma-se que tecnologia no ensino superior à distância é uma possibilidade aberta a uma evolução constante e que será tanto mais efetiva quanto se inscreva no marco de uma formação humana, especialmente quanto à docência, que se estenda por toda a vida, aperfeiçoando-se e evoluindo de forma autônoma e independente.

Nesse sentido, sugere-se que futuras pesquisa analisem a temática, assim como também os reflexos deste momento pandêmico, voltadas a permanência e êxito dos alunos da educação a distância. Ainda considera-se importante que futuros estudos investiguem como as instituições brasileiras estão capacitando os docentes para o desenvolvimento de novas práticas pedagógicas voltadas para o ensino.

\section{Agradecimentos}

Os autores agradecem ao Instituto Federal de Educação, Ciência e Tecnologia de Rondônia/Campus Porto Velho Zona Norte por seu apoio financeiro.

\section{Referências}

Bates, T., Educar na era digital: design, ensino e aprendizagem. São Paulo: Artesanato Educacional, 2016.

Behar, P. A., Modelos pedagógicos em educação a distância. Livro Digital. Porto Alegre: GrupoA, 2014. 
Batista, C. S. M., Gaspar, G. T. T., Junio, S. dos S., Oliveira, V. A. de., \& Silva, A. M. da. (2021). Ensino remoto em um curso técnico presencial: Reflexos de um projeto interdisciplinar no contexto da pandemia. Research, Society and Development, 10(7), e54110716695.

Caldas, L. R. dos R., Teles, M. C., Guimaraes, A. L. R., \& Sousa, J. F. G. de. (2022). Educação a distância durante a pandemia do COVID19: percepção docente, qualidade de vida e ansiedade entre professores universitários de Minas Gerais, Brasil. Research, Society and Development, 11(1), e37511125041.

Carvalho, A. A. A., Multimédia: um conceito em evolução. Revista Portuguesa de Educação, n. 7, a. 12, p. 123-165, ago./2012.

Castells, M., A sociedade em rede. 10 ed. São Paulo: Paz e Terra, 2009.

Dewey, J., Experiência e Educação. 3 ed. Petrópolis: Vozes, 2010.

Freire, P., Educação como prática da liberdade. 34 ed. Rio de Janeiro: Paz e Terra, 2011.

Freitas, C. V., Tecnologias de informação e comunicação na aprendizagem. Lisboa, Instituto de Inovação Educacional, 2013.

Kenski, V. M., Tecnologias e ensino presencial e a distância. 9 ed. Campinas: Papirus, 2012.

Kerckhove, D., Inteligencias em conexión: hacia una sociedad de la web. 3 ed. Barcelona: Gedisa Editorial, 2013.

Martins, I. 1 P., Formação inicial de professores: um debate inacabado. In: Gregório, M, C; Ferreira, S, (org.). Formação inicial de professores. Lisboa: Conselho Nacional de Educação, 2015, p. 193-215.

Morin, E., Introdução ao pensamento complexo. 3. ed. Porto Alegre: Sulina, 2007.

Nóvoa, A., Formação profissional para ambientes tecnológicos em sala de aula. In: NÓVOA, António (org.). Formação contínua de professores: realidade e perspectivas. 3 ed. Portugal: Universidade de Aveiro, 2015, p. 35-43.

Ponte, J. P., As Novas Tecnologias e a Educação. 8 ed. Lisboa: Texto Editora, 2014.

Schon, D. A., Educando o profissional reflexivo: um novo design para o ensino e a aprendizagem. Porto Alegre: Artmed, 2013.

Silva, M., Sala de aula interativa. 5 ed. São Paulo: Loyola, 2010.

Tori, R., Educação sem distância: as tecnologias interativas na redução de distâncias em ensino e aprendizagem. 2. ed. São Paulo: Artesanato Educacional, 2017.

Straubhaar, J.; Larose, R., Comunicação, mídia e tecnologia. Tradução de José Antonio Lacerda Duarte. 2 ed. São Paulo: Thomson, 2008.

Valente, J. M., Second Life e WEB 2.0 na Educação: o potencial revolucionário das novas tecnologias. 2 ed. São Paulo: Novatec Editora , 2012.

Valentini, C. B.; Soares, E. M. S., Aprendizagem em Ambientes Virtuais: compartilhando ideias e construindo cenários. 3. ed. Caxias do Sul: EDUCS, 2014. 